\title{
Optimization of weld bead geometry of MS plate (Grade: IS 2062) in the context of welding: a comparative analysis of GRA and PCA-Taguchi approaches
}

\author{
NITIN KUMAR SAHU ${ }^{1, *}$, ATUL KUMAR SAHU ${ }^{1}$ and ANOOP KUMAR SAHU ${ }^{2}$ \\ ${ }^{1}$ Department of Industrial and Production Engineering, Institute of Technology, Guru Ghasidas \\ Vishwavidyalaya, Bilaspur 495009, India \\ ${ }^{2}$ Department of Mechanical Engineering, National Institute of Technology, Rourkela 769008, India \\ e-mail: nitin83sahu@gmail.com; atul85sahu@gmail.com; anoop17212@gmail.com
}

MS received 1 June 2015; revised 9 June 2016; accepted 25 July 2016

\begin{abstract}
In the last few decades, researchers proceeded their foot for analyzing the weld characteristic index of materials since the development of novel materials began tremendously. Presently, evaluation of the optimum synchronization among considered input factors for materials are even now surviving into ill-defined mode; soliciting novel mathematical models as well as robustly designed decision support systems that could effectively handle nonpartial information (experimental data). In the present reporting, multiobjective optimization dilemmas have been answered in metal inert gas (MIG) welding process using MS plate (Grade: IS 2062) specimen. The considered specimen was checked to harmonize the optimum setting between input factors, for example, welding current, open circuit voltage, and thickness of plate, with respect to obtaining prosperous weld strength as well as bead geometry quality characteristics, for example, tensile strength, bead width, reinforcement, penetration, and dilution. In the present research work, the Taguchi's $\mathrm{L}_{9}$ orthogonal array (OA) design was preferred to conduct the experiments on MS plate (Grade: IS 2062) specimens in the domain of MIG welding process. Thereafter, the evaluated multiple objectives transformed into a single response via exploration of grey relation analysis (GRA) and principal component analysis (PCA) approaches to determine the optimum setting between input factors. Next, the outset of signal-to-noise ratio ( $\mathrm{S} / \mathrm{N}$ ratio) along with Analysis of variance (ANOVA) productively was utilized to determine the priority weights against the defined input factors (significant factor). The significant contribution of the present report was to propose a robustly designed decision support system that could assist the readers/researchers to resolve the discussed problems.
\end{abstract}

Keywords. ANOVA; orthogonal array; signal-to-noise ratio; Taguchi approach; weld bead geometry.

\section{Introduction}

In the present era, welding has been cited as a foremost fabrication technique for joining two materials/specimens. Welding has broad application in most of the industrial units on account of its unique features associated: fabrication of dissimilar materials, gate fabrication, and repairmen perspective, etc. Currently, metal inert gas (MIG) welding is well known rather the than entire welding process due to its simplicity, ease of handling, least fabrication cost, etc. MIG welding was developed by Humphry Davys in the 1940s. MIG welding is being considered as a semi-automated welding that continuously keeps filling the joint being welded. MIG welding is most ordinarily employed from fabrication perspectives in shops.

*For correspondence
Recently, it has been investigated by researchers that both the metallurgical attributes of weld metal and heataffected zone (HAZ) must be taken into account as it explicitly upshots the characteristic index as well as mechanical properties of the welded joints. In addition, it has been found that the microstructure of the weldment appears dissimilar as compared to its base metal while welding is proceeded on particulate material. Therefore, change in the microstructure affects the mechanical properties of the weld and solicits indeed action to be controlled. In preview years, several researches have been conducted with viewing the outputs of welded material for escalating welding performance as well as preserving the qualities in welding materials.

In the welding process, mechanical properties such as hardness, impact strength, yield strength, and resistance to wear and corrosion are major characteristics of the weldment. These must be taken as significant outputs to be 


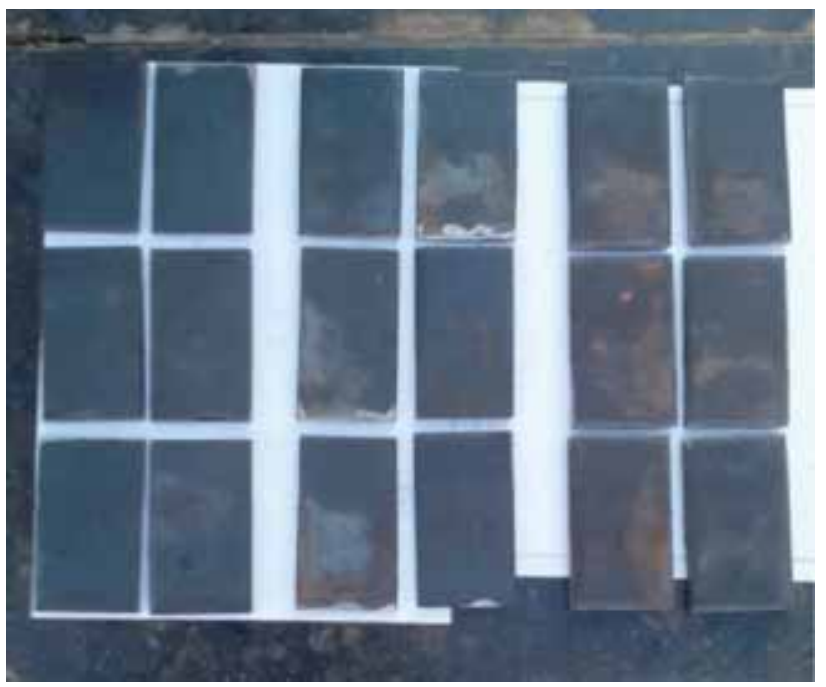

Figure 1. MS plate (Grade: IS 2062) experimental specimen.

attained and optimized [1]. Weld excellence principally depends on mechanical properties and HAZ of the weld metal, which relays on weld bead geometry [2]. Critical aspects such as durability, robustness, soundness, and sturdiness are the basic needs of the goods that should be maximized to a desirable extent.

The literature survey conducted dealt with application of MIG welding in industries, mathematical model as well as approaches to resolve the optimization dilemma in manufacturing realms.

Chandel et al [3] presented theoretical predictions of the upshot of current, electrode polarity, electrode diameter, and electrode extension upon the melting rate, bead height, bead width, and weld penetration in the context of submerged arc welding (SRW). Jiang et al [4] investigated the influence of welding wire upon the microstructure, tensile strength, and impact toughness of Q550 steel weld joints. Farias [5] examined the operational behaviors of ANSI/ AWS A5.1-91 E6013 type electrodes when 0, 8, and 16\% of quartz $\left(100 \% \mathrm{SiO}_{2}\right)$ was substituted by wollastonite (calcium silicate, $50 \% \mathrm{SiO}_{2}-50 \% \mathrm{CaO}$ ) in the coating composition. The result concluded that the substitution of quartz by wollastonite in the coating escalated slag basicity, but diminished the entire weld metal silicon as well as the oxygen content. Tarng et al [6] employed Taguchi Parameter Design (TPD) approach with the aim to optimize the multiple weld qualities of submerged arc welding (SAW) process parameters for hard facing. Lung et al [7] explored grey analysis-based Taguchi approach in perspective to effectively optimize multiple quality characteristics of Nd: YAG laser-welded titanium alloy plates. Ilo et al [8] implemented the grey relational analysis combined with the Taguchi approach for optimizing the plasma transferred arc (PTA) processing in hard facing of $\mathrm{WC} /$ W2C-reinforced Ni-based metal matrix composites
(MMCs). Bai et al [9, 10] established the synchronous acquisition system for droplet image inspection and arc electric signals. Thereafter, experiment conducted to investigate the droplet transition characteristics of aluminum alloys in the plasma-MIG welding process. The results assessed that metastable spray transfer and projected transfer modes seemed to be the upmost optimal modes rather than globular transfer and short circuiting transfer modes. Zhang et al [11] conducted single-pass hybrid laser-MIG welding on highly reflective T2 4-mm thick copper without preheating and observed a significant synergy effect. The effects of primary welding parameters on the shape and integrity of copper joints were studied through bead-on-plate (BOP) welding test. Finally, results of X-ray inspection and infrared photography showed that both porosity susceptibility and crack susceptibility were highly dependent on welding heat input or energy coupling efficiency. Bai et al [10] studied the upshot of plasma-MIG welding parameters on aluminum weld porosity. A 5A06 aluminum alloy in the form of $\mathrm{V}$-grooves was considered for mechanical tests under the X-ray diffractometry analysis. The experimental results indicated that plasma gas flow rate broadly upshots the weldment rather than other factors of MIG welding aligned; voltage, welding speed, wire feed rate, and plasma current. Maggiolino and Schmid [12] compared the corrosion resistance of AA6060T5 and AA6082T6 plates jointed by friction stir welding (FSW) and MIG welding, respectively. The result revealed that the FSW distributed more corrosion resistance as compared to MIG welding on jointed plates. Nagesh and Datta [13] explored Artificial Neural Networks (ANNs) to model the shielded metal-arc welding process. A back-propagation neural network was implemented to correlate the welding process variables for estimating the weld bead as well as penetration geometric parameters. Murugan and Gunaraj [14] developed a mathematical model in order to predict and control the critical dimensions of the weld bead geometry and shape relationships of pipe in the context of SAW. Shen et al [15] investigated the influences of heat input upon weld bead geometry of submerged arc welded ASTM A709 Grade 50 steel joints. Moreover, how the variation in heat input influences bead reinforcement, bead width, penetration depth, etc., was examined. Lee and Um [16] compared the results of multiple regression analysis and ANN approaches concurrently to predict the geometry of the back-bead in the context of gas metal-arc welding.

In the present reporting, the critical weldment parameters have been taken into account in order to maximize weld quality that thump on the demands of manufacturers for producing their products economically. MIG welding is a multi-factor-driven process where the weld strength depends on several variables such as welding current, open circuit voltage, thickness of plate, wire feed rate, shielding atmosphere, and type of power source. Hence, it is necessary to find the best possible strength and bead geometry conditions for producing the desired quality weld by opting 
for appropriate settings of these multifactors in such a way that all the objectives must be fulfilled simultaneously.

\section{Motivation to conduct experiments solely on MS plate (Grade: IS 2062) specimen}

The chief motivation to carry out the experiments individually upon MS plate (Grade: IS 2062) material among miscellaneous materials was its paramount internal and external characteristics, for example, rust resistance, durability, and strength, with reasonable price as well as huge availability. Due to the said characteristics, the said material found its major applicability in different realms for fabrication aligned: railways, window grills manufacturers, collapsible gate manufacturers, automobile fabricators, etc. Presently, it has been found that the characteristic index of the said material is being leveraged via varying input factors during the welding. So, it became indeed necessary to conduct experiments on MS plate (Grade: IS 2062) specimen to determine the optimum setting between the input factors with respect to obtain the maximum desirable characteristic index in the context of MIG welding in order that the welding operation can be brought about while preserving the qualities of the weldment.

\section{Problem formulation and conducted experiments}

In the present work, experiments have been conducted in the context of process parameters of MIG welding in order to obtain BOP weldment upon mild steel plates as shown in table 1. Each plate encompasses the dimension $90 \mathrm{~mm} \times 50 \mathrm{~mm} \times \mathrm{XX} \mathrm{mm}$ (where $\mathrm{XX}$ is the plate thickness at different levels). A weld gap of $3 \mathrm{~mm}$ is preserved between two plates during welding on varying input factors.

MIG welding process is used in MS plate (Grade: IS 2062) specimen, as shown in figure 1 , to obtain an appropriate joint design for the service exposed conditions encountered in actual application. Experiments have been performed in Thyristor Controlled MIG/MAG Arc Welding Power Source-Model No.: KR-250 including specification shown in table 2. A 1-mm copper-coated continuous solid wire (MIGFAST-1) coding: AWS/SFA-5.18ER70S-6 including description, shown in table 3 , is used with a welding speed of $40-45 \mathrm{~cm} / \mathrm{min}$.

In full factorial design, the number of experiment runs exponentially increases as the number of factors as well as their level increases the results of enormous experimentation cost and considerable time. Therefore, in the present study, $\mathrm{L}_{9}$ has been explored in domain of three conventional process parameters, viz., voltage (OCV), plate thickness, and current (SSC), varied at three different levels as depicted in table 4 and Taguchi's $\mathrm{L}_{9}$ (orthogonal array) experimental runs as depicted in table 5.

The visual inspections carried out after welding and appearance of the weld bead are revealed in table 6. After welding, the specimens have been smoothened by means of emery paper and cloth polishing. Parameters associated with bead geometry in terms of bead width, reinforcement (bead height), and depth of penetration have been measured by optical Trinacular metallurgical microscope. Moreover, ultimate tensile strength measured by Computerized UTE60. Sr. No. 7/2008-367 with maximum capacity of $600 \mathrm{KN}$ is depicted in figure 2.

Experimental information related to ultimate tensile strength and bead geometry is furnished in table 7. Evaluated entire (information) output data utilized for analyzing and evaluating the optimal setting between input factor/parameters. The experiments are conducted to achieve the desired quality in weldment in terms of bead strength and geometry.

\section{Mathematical modeling}

\subsection{Grey relational analysis (GRA) approach}

The grey system was developed by Dr. Deng, which dealt with information between black and white, i.e., black represents incomplete information and white represents complete information. Grey relational analysis (GRA) is employed to tackle the vague, inexplicit, imprecise, nonexact information in an experimental domain. It assists to compensate the shortcoming in statistical regression. The concept of GRA provides efficient solution corresponding to existing approaches to fruitfully handle the uncertainty, multiresponse, and discrete data dilemma. It can be carried out via the following steps:

Table 1. Description of specimen-MS plate (Grade: IS 2062).

\begin{tabular}{|c|c|c|c|c|c|c|c|c|}
\hline \multicolumn{6}{|c|}{ Chemical composition } & \multicolumn{3}{|c|}{ Mechanical properties } \\
\hline $\begin{array}{l}\mathrm{C} \% \\
\max \end{array}$ & $\begin{array}{l}\operatorname{Mn} \% \\
\max \end{array}$ & $\begin{array}{l}\mathrm{S} \% \\
\max \end{array}$ & $\begin{array}{l}\mathrm{P} \% \\
\max \end{array}$ & $\begin{array}{l}\mathrm{Si} \% \\
\max \end{array}$ & $\begin{array}{l}\text { C.E.\% } \\
\max \end{array}$ & $\begin{array}{l}\text { Ultimate tensile strength } \\
(\mathrm{MPa})\end{array}$ & $\begin{array}{l}\text { Yield strength }(\mathrm{MPa}) \\
\min \end{array}$ & $\begin{array}{c}\% \text { Elongation } \\
\text { min }\end{array}$ \\
\hline 0.23 & 1.5 & 0.05 & 0.05 & 0.04 & 0.42 & 410 & 250 & 23 \\
\hline
\end{tabular}


4.1a Data preprocessing: It is a process to transfer the original sequence into a comparable sequence for apiece performance characteristic (grey relational generation). In grey relational generation, the normalized bead width and reinforcement corresponding to lower-the-better (LB) criterion can be expressed as

$$
x_{i}(k)=\frac{\max y_{i}(k)-y_{i}(k)}{\max y_{i}(k)-\min y_{i}(k)}
$$

Ultimate tensile strength, bead penetration, and dilution should follow larger-the-better criterion, which can be expressed as

$$
x_{i}(k)=\frac{y_{i}(k)-\min y_{i}(k)}{\max y_{i}(k)-\min y_{i}(k)}
$$

where $x_{i}(k)$ is the value after the grey relational generation, $\min y_{i}(k)$ is the smallest value of $y_{i}(k)$ for the $k$ th response, and $\left.\max y_{i}(k)\right)$ is the largest value of $y_{i}(k)$ for the $k$ th response.

4.1b Evaluation of $\Delta_{o i}$ : It stands for the deviation sequence from the ideal sequence for apiece of the responses

$$
\Delta_{o i}(\text { difference of the absolute value })=\left\|x_{0}(k)-x_{i}(k)\right\|
$$

where $x_{0}(k)(k=1,2,3 \ldots, 9)$ for the responses.

4.1c A grey relational coefficient: The grey relational coefficient $\xi_{i}(k)$ can be calculated as

$$
\xi_{i}(k)=\frac{\Delta_{\min }+\psi \Delta_{\max }}{\Delta_{0 i}(k)+\psi \Delta_{\max }}
$$

where $\psi$ is the distinguishing coefficient $0 \leq \psi \leq 1$; $\Delta_{\min }=\forall j^{\min } \in i \forall k^{\min }\left\|x_{0}(k)-x_{j}(k)\right\|=$ the smallest value
Table 4. Process parameters and their limits.

\begin{tabular}{lccrrr}
\hline & & & \multicolumn{3}{c}{ Level of factors } \\
\cline { 3 - 6 } Parameters & Notations & Units & 1 & \multicolumn{1}{c}{2} & 3 \\
\hline Welding current & $\mathrm{A}$ & Amp & 230 & 260 & 290 \\
Voltage & $\mathrm{V}$ & Volt & 20 & 22 & 24 \\
Plate thickness & $\mathrm{Pt}$ & $\mathrm{mm}$ & 5 & 6 & 8 \\
\hline
\end{tabular}

Table 5. Taguchi's L9 orthogonal array design.

\begin{tabular}{lccc}
\hline Experiment no. & Welding current & Voltage & Plate thickness \\
\hline 1 & 1 & 1 & 1 \\
2 & 1 & 2 & 2 \\
3 & 1 & 3 & 3 \\
4 & 2 & 1 & 2 \\
5 & 2 & 2 & 3 \\
6 & 2 & 3 & 1 \\
7 & 3 & 1 & 3 \\
8 & 3 & 2 & 1 \\
9 & 3 & 3 & 2 \\
\hline
\end{tabular}

of $\quad \Delta_{o i} ; \quad \Delta_{\max }=\forall j^{\max } \in i \forall k^{\max }\left\|x_{0}(k)-x_{j}(k)\right\|=$ largest value of $\Delta_{o i}$.

Grey relational grade $\gamma_{i}$

It can be computed as

$$
\gamma_{i}=\frac{1}{n} \sum \xi_{i}(k)
$$

where $n$ is the number of process responses. The definition of grey relational grade in the course of grey relational analysis (GRA) is to reveal the degree of relation between the nine sequences $\left[x_{0}(k)\right.$ and $\left.x_{i}(k), i=1,2, \ldots\right]$.

Table 2. Specification of Thyristor controlled MIG/MAG arc welding equipment (model no.: KR-250).

\begin{tabular}{lccc}
\hline Specification & Range & Specification & Range \\
\hline Mains voltage (V) & 380 & Output current (A) & $50-250$ \\
Frequency (Hz) & $50 / 60$ & Rated duty cycle (\%) & 60 \\
Input capacity (KVA) & 7.6 & Dimensions (cm) & $63 \times 38 \times 75$ \\
Wire dia. (mm) & $0.6-1.0$ & Weight (kg) & 85 \\
\hline
\end{tabular}

Table 3. Description of feed wire (copper-coated continuous solid wire) used in MIG/MAG welding.

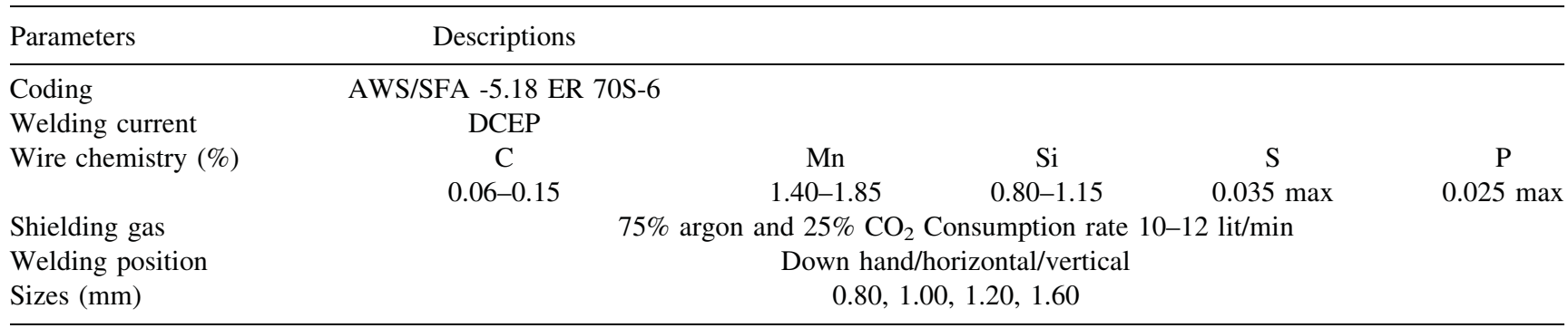


Table 6. Results of visual inspections after welding.

\begin{tabular}{lr}
\hline Experiment no. & Appearance of the weld bead \\
\hline 1 & Narrow, straight and thin weld bead with moderate bead height. Uniform metal deposition \\
2 & Straight, uniform medium bead, slight wider than previous. More bead height than previous, uniform metal deposition \\
3 & Apparently perfect weld bead, not so much wide. Deposition satisfactory with medium bead height \\
4 & Narrow, straight and thin weld bead with moderate bead height. Uniform metal deposition \\
5 & Non uniform wider bead. Smooth bead height with less appearance \\
6 & Very bad quality, slight wider than previous. High non-uniform metal deposition with high bead height. \\
7 & Straight and thin weld bead with smooth bead height, deposition satisfactory. \\
8 & Apparently perfect weld bead, not so much wide. Uniform metal deposition with medium bead height \\
9 & Straight and medium wide weld bead with smooth bead height. Slight wider than previous, uniform metal deposition \\
\hline
\end{tabular}

\subsection{Principal component analysis (PCA) approach}

The principal component analysis (PCA) is a path to recognize patterns in the correlated data and expressing the data in such a way so as to highlight their similarities and differences [2]. The main advantage of PCA is that once the patterns in data have been identified, the data can be compressed, i.e., by reducing the number of dimensions, without much loss of information. The methods involved in PCA are discussed below:

1. Getting some data

2. Normalization of data

3. Calculation of covariance matrix

4. Interpretation of covariance matrix.

The normalized data have then been utilized to construct a variance-covariance matrix $\mathrm{M}$, which is illustrated as follows:

$$
N_{k, l}=\frac{\operatorname{Cov}\left(Y_{i, k}^{*}, Y_{i, l}^{*}\right)}{\sqrt{\operatorname{Var}\left(Y_{i, k}^{*}\right) \operatorname{Var}\left(Y_{i, l}^{*}\right)}} M=\left[\begin{array}{c}
N_{1,1} N_{1,2} \ldots N_{1, u} \\
N_{2,1} N_{2,2} \ldots N_{2, P} \\
: \ldots \ldots \\
N_{q, 1} N_{q, 2} \ldots N_{q, p}
\end{array}\right]
$$

where $u$ stands for the number of quality characteristics, and $P$ stands for the number of experimental runs. Then, eigenvectors and eigenvalues of matrix $M$ can be computed, which are denoted by $\vec{V}_{J}$ and $\lambda_{j}$, respectively. In PCA, the eigenvector $\vec{V}_{J}$ represents the weighting factor of $j$ number of quality characteristics of the $j$ th principal component. For example, if $Q_{j}$ represents the $j$ th quality characteristic, the $j$ th principal component $\psi_{j}$ can be treated as a quality indicator with the required quality characteristic.

$$
\psi_{j}=V_{J 1} Q_{1}+V_{J 2} Q_{2} \ldots V_{J J} Q_{J}=\vec{V}_{J} \cdot \vec{Q}
$$

It is to be noted that every principal component $\psi_{j}$ represents a certain degree of explanation of the variation of quality characteristics, namely, the accountability proportion (AP). When several principal components are accumulated; it increases the accountability proportion of quality characteristics. This is denoted as cumulative accountability proportion (CAP). In the present work, the composite principal component $\psi$ has been defined as the combination of principal components with their individual eigen values. This composite principal component $\psi$ serves as the representative of multiquality responses called multi/composite quality indicator.

If a quality characteristic $Q_{j}$ strongly dominates in the $j$ th principal component, this principal component becomes the major indicator of such a quality characteristic. It should be noted that one quality indicator may often represent all the multiquality characteristics. Selection of individual principal components $\left(\psi_{j}\right)$ to be included in the composite quality indicator $\psi_{j}$ depends on their individual AP.

After calculating the individual principal components, the composite quality indicator is to be defined, which is the representative of multicharacteristics of the weld bead geometry. In the study, it has been proposed that the composite principal component $\psi_{1}$ can be calculated as shown below.

$$
\psi_{j}=\left(\psi_{2 i}^{2}+\psi_{2 i}^{2}+\psi_{3 i}^{2}+\psi_{4 i}^{2}\right)^{1 / 2}
$$

Here $i$ is the experiment number.

\subsection{Taguchi approach}

Taguchi's philosophy (known as Robust Design approach) was pioneered by Dr. Genichi Taguchi. He was a Japanese quality management consultant, adverted to significantly improve engineering efficiency. Taguchi approach is for designing high-eminence manufacturing system based on orthogonal array experiments. This approach provides a much-reduced variance for the experiment with upmost favorable setting of process control parameters. The signalto-noise $(\mathrm{S} / \mathrm{N})$ ratio is an ideal metric to look concurrently on a range of control factors for accomplishing optimized objective functions. The $\mathrm{S} / \mathrm{N}$ ratios ordinarily pursue three standard associates: lower the better (LB), higher the better 

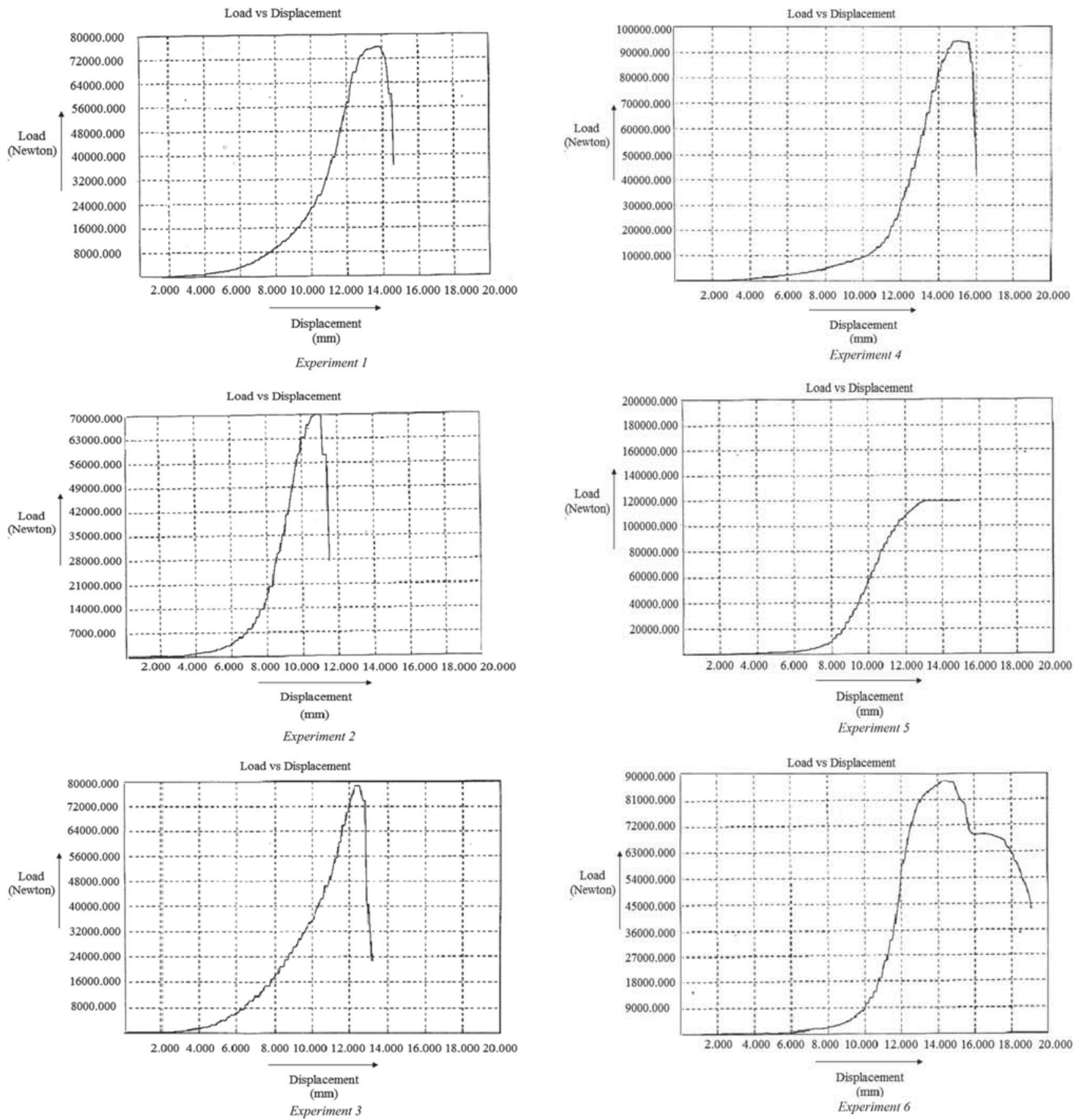

Figure 2. Plots obtained from computerized UTM (model no. $U T E-60)$ for ultimate tensile strength.

(HB) and Nominal is best (NB), as shown in Eqs. (1), (2), and (3), respectively. The ANOVA concept is the statistical tool/approach being explored to interpret experimental data and make the necessary conclusions regarding which parameters upshot the performance via reducing and controlling variation of a product or process.

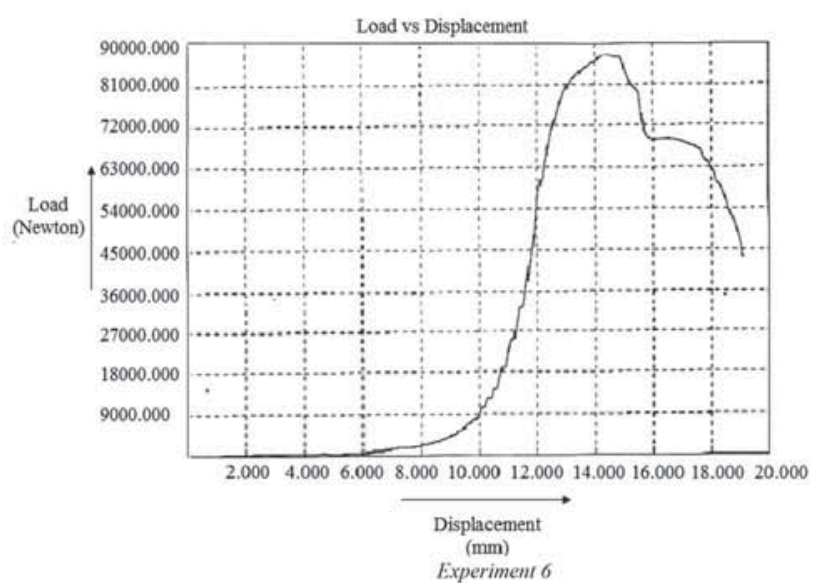

Figure 2. continued

\subsection{Lower the better (LB)}

Performance characteristics, whose values are preferred when low, are calculated using this approach. Such factors are bead width and reinforcement. The following equation is used to calculate the $\mathrm{S} / \mathrm{N}$ ratio for LB type of characteristics. 

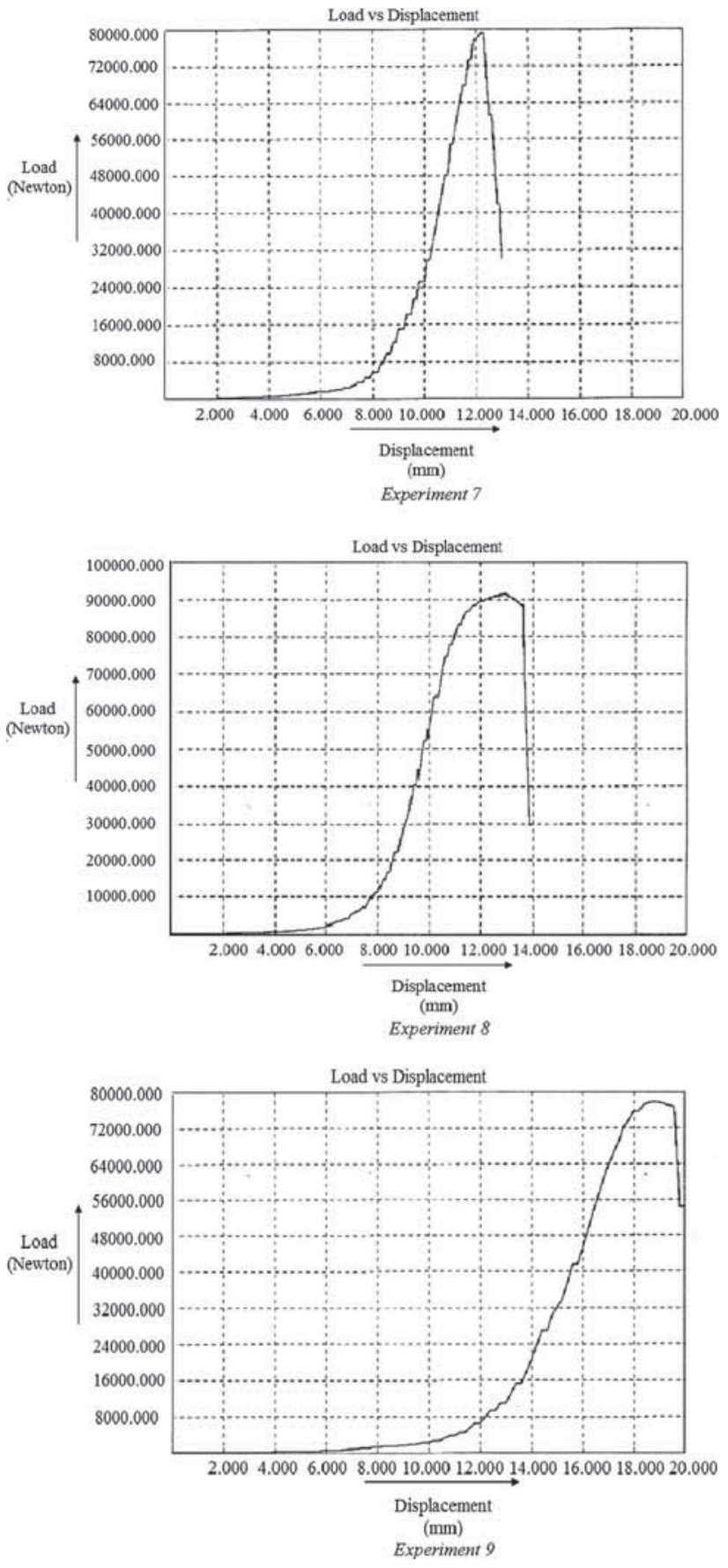

Figure 2. continued

$$
(\mathrm{S} / \mathrm{N})_{\mathrm{LB}}=-10 \log \frac{1}{n}\left[\sum_{j=1}^{n} y_{j}^{2}\right]
$$

\subsection{Higher the better $(H B)$}

Performance characteristics, whose values are preferred when high, are calculated using this approach. Such factors are ultimate tensile strength, weld penetration, and dilution. The following equation is used to calculate the $\mathrm{S} / \mathrm{N}$ ratio for HB type of characteristics.

$$
(\mathrm{S} / \mathrm{N})_{\mathrm{HB}}=-10 \log \frac{1}{n}\left[\sum_{j=1}^{n} \frac{1}{y_{j}^{2}}\right]
$$

\subsection{Nominal the best $(N B)$}

Performance characteristics, whose values are preferred when nominal, are calculated using this approach. Such factors are dimensions and appearance. The following equation is used to calculate the $\mathrm{S} / \mathrm{N}$ ratio for $\mathrm{NB}$ type of characteristics.

$$
(\mathrm{S} / \mathrm{N})_{\mathrm{NB}}=-10 \log \frac{1}{n}\left[\sum_{j=1}^{n}\left(y_{j}-y_{0}\right)^{2}\right]
$$

where $y_{j}$ is the value of the characteristic in an observation $j, y_{0}$ is the nominal value of the characteristic, and $n$ is the total number of experiments run.

\section{Rationale to implement GRA and PCA-based Taguchi approach concurrently}

The $\mathrm{L}_{9}$ has been referred as feasible experiments for diminishing time, operator cost and material price. Subsequently, GRA and PCA are both implemented concurrently in order to evaluate the Multiparameter Characteristic Index (MPCI), called as overall grey relational grade and composite principle component, respectively. Thereafter, $\mathrm{S} / \mathrm{N}$ ratio statistical analysis for the priority weights against the defined input factors is carried out on MPCI obtained by grey relational analysis (GRA) and principal component analysis (PCA) to robustly assess the results. Eventually, it found out that both applied approaches possess their validly for determining the optimum setting between input factors.

\section{Confirmatory experiment and validation}

\subsection{Confirmatory experiment}

The estimated overall grey relational grade/composite principal component $\widehat{\gamma}$ using the optimal level of the design parameters is calculated as

$$
\widehat{\gamma}=\gamma_{m}+\sum_{i=1}^{0}\left(\bar{\gamma}_{i}-\gamma_{m}\right)
$$

where $\gamma_{m}$ is the total mean grey relational grade/composite principal component, $\bar{\gamma}_{i}$ is the mean grey relational grade/composite principal component at the optimal level, 
Table 7. Experimental data.

\begin{tabular}{|c|c|c|c|c|c|}
\hline Experiment no. & Ultimate tensile strength $\left(\mathrm{N} / \mathrm{mm}^{2}\right)$ & Bead width (mm) & Reinforcement (mm) & Penetration (mm) & Dilution $(\%)$ \\
\hline 1 & 246.41 & 9.6 & 3.20 & 4.90 & 0.3786 \\
\hline 2 & 246.85 & 9.9 & 3.28 & 5.70 & 0.4013 \\
\hline 3 & 316.88 & 9.7 & 2.76 & 7.60 & 0.5202 \\
\hline 4 & 300.00 & 9.6 & 3.27 & 5.80 & 0.4137 \\
\hline 5 & 345.82 & 10.6 & 1.48 & 4.01 & 0.4940 \\
\hline 6 & 273.19 & 11.1 & 3.34 & 4.99 & 0.3395 \\
\hline 7 & 216.75 & 9.6 & 1.82 & 7.98 & 0.6356 \\
\hline 8 & 296.97 & 9.7 & 2.28 & 4.98 & 0.4624 \\
\hline 9 & 220.66 & 9.8 & 1.90 & 5.01 & 0.5068 \\
\hline
\end{tabular}

and 0 is the number of the main design parameters that affect the quality characteristics. After statistical analysis, it has been observed that there is best compliance between the two (improvement in overall grey relational grade/composite principal component). This study proves the validity of the proposed approach to evaluate the optimum setting between input factor/parameters tackling the multiple objectives simultaneously.

\subsection{Analysis of variance (ANOVA)}

ANOVA is utilized to decide the levels of significance of input factor/parameters. ANOVA is the statistical approach that is used to interpret experimental data and also make the necessary conclusions about input parameters (which parameter significantly affects the performance). The approach is very useful to identify the significant factors of input parameters or interaction of parameters upon a particular response. It separates the total variability of the response (sum of squared deviations about the grand mean) into contributions rendered by each of the parameter/factor and the error. Thus

$$
\begin{gathered}
S S_{T}=S S_{F}+S S_{E} \\
S S_{T}=\sum_{j=1}^{p}\left(\gamma_{j}-\gamma_{m}\right)^{2}
\end{gathered}
$$

where $S S_{T}$ is the total sum of squared deviations about the mean, $\gamma_{j}$ is the mean response for $j$ th experiment, $\gamma_{m}$ is the grand mean of the response, $P$ is the number of experiments in the orthogonal array, $S S_{F}$ is the sum of squared deviations due to each factor, and $S S_{E}$ is the sum of squared deviations due to error.

In ANOVA, mean square deviation is defined as

$$
\mathrm{SS}=\frac{\mathrm{SS}(\text { Sum of squared deviation })}{\mathrm{DF}(\text { Degree of freedom })}
$$

F-value of Fisher's F ratio (Variance ratio) is defined as

$$
F=\frac{\text { MS of a term }}{\text { MS for the error term }}
$$

\section{Procedural steps}

The following steps were followed to evaluate and validate the result:

\section{Step 1: L9 (Orthogonal Array)}

Preliminary, the $\mathrm{L}_{9}$ (orthogonal array) experiments conducted on Grade: IS 2062 specimens in relation to input factors, e.g., welding current, voltage, plate, and thickness; with respect to obtaining maximum and minimum value of beneficial and nonbeneficial outputs, respectively, in experimental domain of MIG welding.

Step 2: Multiperformance Characteristic Index (MPCI) Next, in accordance with the nature of outputs, considered output/objectives, e.g., ultimate tensile, strength, bead width, reinforcement, penetration, and dilution, have been transformed into single objective function (MPCI) called overall grey relational grade and composite principal component for implemented GRA and PCA, respectively.

\section{Step 2.1: Evaluation of overall grey relational grade}

In order to evaluate the overall grey relational grade, preliminary evaluated outputs, e.g., ultimate tensile, strength, bead width, reinforcement, penetration, and dilution, carried out into the stage of normalization by using Eqs. (1) and (2), tabulated in table 8. Next, the deviation sequence from the ideal sequence for apiece of the responses $\Delta_{o i}$ evaluated by using Eq. (3), depicted in table 9. Subsequently, the grey relational coefficient of performance characteristics brought into evaluation stage by using Eq. (4), depicted in table 10. At last, the overall grey relational grade as has been evaluated for each of multiple characteristic outputs by using Eq. (5), showed in table 11. Response table (mean) for overall grey relational grade, showed in table 12 . 
Table 8. Data preprocessing of each performance characteristic (grey relational generation).

\begin{tabular}{|c|c|c|c|c|c|}
\hline $\begin{array}{l}\text { Experiment no. } \\
\text { Ideal sequence }\end{array}$ & $\begin{array}{l}\text { Ultimate tensile strength }\left(\mathrm{N} / \mathrm{mm}^{2}\right) \\
1\end{array}$ & $\begin{array}{l}\text { Bead width }(\mathrm{mm}) \\
1\end{array}$ & $\begin{array}{c}\text { Reinforcement }(\mathrm{mm}) \\
1\end{array}$ & $\begin{array}{l}\text { Penetration }(\mathrm{mm}) \\
1\end{array}$ & $\begin{array}{c}\text { Dilution }(\%) \\
1\end{array}$ \\
\hline 1 & 0.230 & 1.000 & 0.075 & 0.224 & 0.132 \\
\hline 2 & 0.233 & 0.800 & 0.032 & 0.426 & 0.209 \\
\hline 3 & 0.776 & 0.933 & 0.312 & 0.904 & 0.610 \\
\hline 4 & 0.645 & 1.000 & 0.038 & 0.451 & 0.251 \\
\hline 5 & 1.000 & 0.333 & 1.000 & 0.000 & 0.522 \\
\hline 6 & 0.437 & 0.000 & 0.000 & 0.247 & 0.000 \\
\hline 7 & 0.000 & 1.000 & 0.817 & 1.000 & 1.000 \\
\hline 8 & 0.622 & 0.933 & 0.570 & 0.244 & 0.415 \\
\hline 9 & 0.030 & 0.867 & 0.774 & 0.252 & 0.565 \\
\hline
\end{tabular}

Table 9. Evaluation of $\Delta_{0 \mathrm{i}}$ for each of the responses.

\begin{tabular}{|c|c|c|c|c|c|}
\hline $\begin{array}{l}\text { Experiment no. } \\
\text { Ideal sequence }\end{array}$ & $\begin{array}{l}\text { Ultimate tensile strength }\left(\mathrm{N} / \mathrm{mm}^{2}\right) \\
1\end{array}$ & $\begin{array}{l}\text { Bead width }(\mathrm{mm}) \\
1\end{array}$ & $\underset{1}{\text { Reinforcement (mm) }}$ & $\begin{array}{l}\text { Penetration }(\mathrm{mm}) \\
1\end{array}$ & $\begin{array}{c}\text { Dilution }(\%) \\
1\end{array}$ \\
\hline 1 & 0.7702 & 0.0000 & 0.9247 & 0.7758 & 0.8680 \\
\hline 2 & 0.7668 & 0.2000 & 0.9677 & 0.5743 & 0.7913 \\
\hline 3 & 0.2242 & 0.0667 & 0.6882 & 0.0957 & 0.3897 \\
\hline 4 & 0.3550 & 0.0000 & 0.9624 & 0.5491 & 0.7494 \\
\hline 5 & 0.0000 & 0.6667 & 0.0000 & 1.0000 & 0.4782 \\
\hline 6 & 0.5627 & 1.0000 & 1.0000 & 0.7531 & 1.0000 \\
\hline 7 & 1.0000 & 0.0000 & 0.1828 & 0.0000 & 0.0000 \\
\hline 8 & 0.3785 & 0.0667 & 0.4301 & 0.7557 & 0.5849 \\
\hline 9 & 0.9697 & 0.1333 & 0.2258 & 0.7481 & 0.4350 \\
\hline
\end{tabular}

Table 10. Grey relational coefficient of each performance characteristics (with $\psi=0.5$ ).

\begin{tabular}{|c|c|c|c|c|c|}
\hline $\begin{array}{l}\text { Experiment no. } \\
\text { Ideal sequence }\end{array}$ & $\begin{array}{l}\text { Ultimate tensile strength }\left(\mathrm{N} / \mathrm{mm}^{2}\right) \\
1\end{array}$ & $\begin{array}{l}\text { Bead width }(\mathrm{mm}) \\
1\end{array}$ & $\begin{array}{c}\text { Reinforcement (mm) } \\
1\end{array}$ & $\begin{array}{l}\text { Penetration }(\mathrm{mm}) \\
1\end{array}$ & $\begin{array}{c}\text { Dilution }(\%) \\
1\end{array}$ \\
\hline 1 & 0.3936 & 1.0000 & 0.3509 & 0.3919 & 0.3655 \\
\hline 2 & 0.3947 & 0.7143 & 0.3407 & 0.4654 & 0.3872 \\
\hline 3 & 0.6904 & 0.8824 & 0.4208 & 0.8393 & 0.5620 \\
\hline 4 & 0.5848 & 1.0000 & 0.3419 & 0.4766 & 0.4002 \\
\hline 5 & 1.0000 & 0.4286 & 1.0000 & 0.3333 & 0.5111 \\
\hline 6 & 0.4705 & 0.3333 & 0.3333 & 0.3990 & 0.3333 \\
\hline 7 & 0.3333 & 1.0000 & 0.7323 & 1.0000 & 1.0000 \\
\hline 8 & 0.5692 & 0.8824 & 0.5376 & 0.3982 & 0.4609 \\
\hline 9 & 0.3402 & 0.7895 & 0.6889 & 0.4006 & 0.5348 \\
\hline
\end{tabular}

Step 2.2: Evaluation of composite principal component analysis

After evaluating the overall grey relational grade, the evaluation of the composite principal component has carried out with exploration of PCA. For the above computation perspective, once more the evaluated normalized outputs have been availed for evaluating eigenvectors, eigenvalues, AP, and CAP with the exploration of Eq. (6), shown in table 13. Next, on the basis of the evaluated results, the principal components are observed for experiments (L9) carried out using Eqs. (6) and (7), depicted in table 14. Eventually, the entire evaluated principal component matrix is transformed into composite principal component using Eq. (8) as shown in table 15.

Step 3: Evaluation of Synchronization among input factors After evaluating the MPCI via GRA and PCA approach, the S/N ratio for the overall grey relational grade (GRG) and composite principal component (CPC) was evaluated. Thereafter, Eqs. (9), (10) and (11) were employed in order to evaluate the $\mathrm{S} / \mathrm{N}$ ratio, as shown in tables 11 and 15 for overall GRG and CPC, respectively. Therefore, optimum setting among input factors 
Table 11. Grey relational grade.

\begin{tabular}{lcr}
\hline Experiment no. & Overall grey relational grade & S/N ratio (higher-the-better) \\
\hline 1 & 0.50040 & -6.01366 \\
2 & 0.46045 & -6.73628 \\
3 & 0.67897 & -3.36297 \\
4 & 0.56070 & -5.02543 \\
5 & 0.65461 & -3.68038 \\
6 & 0.37390 & -8.54495 \\
7 & 0.81312 & -1.79687 \\
8 & 0.56963 & -4.88816 \\
9 & 0.55079 & -5.18032 \\
\hline
\end{tabular}

Table 12. Response table (mean) for overall grey relational grade.

\begin{tabular}{lcccc}
\hline \multirow{2}{*}{ Factor } & \multicolumn{3}{c}{ Grey relational grade } & \\
\cline { 2 - 4 } & Level 1 & Level 2 & Level 3 & Delta \\
\hline Welding current & 0.54661 & 0.52973 & 0.64451 & 0.11478 \\
Voltage & 0.62474 & 0.56156 & 0.53455 & 0.06318 \\
Plate thickness & 0.48131 & 0.52398 & 0.71557 & 0.23426 \\
\multicolumn{2}{l}{ Total mean grey relational grade $=0.57362$} &
\end{tabular}

Delta $=$ range $($ maximum - minimum $)$ showed similar results as $A_{3} V_{1} P t_{3}$ evaluated via overall GRG and CPC. Moreover, response means evaluated by using Eqs. (13), (14), and (15) for overall GRG and CPC, respectively, are depicted in tables 12 and 16.

Step 4: Comparative analysis of GRA and PCA based on S/N ratio statistical approach

The comparative statistical analysis has been carried out based on outcomes obtained by the overall GRG and CPC based on S/N ratio statistical approach. It has been found that both approaches depicted similar optimum result $\left(A_{3} V_{l} P t_{3}\right)$, as shown in figures 3,4 , and 5.

Table 13. (Analysis of covariance matrix) Eigen values, eigenvectors, accountability proportion (AP) and cumulative accountability proportion (CAP) computed for the four major quality indicators.

\begin{tabular}{|c|c|c|c|c|}
\hline Principle component & Eigen vectors & Eigen value & AP & CAP \\
\hline$\psi_{1}$ & $(0.2490,-0.4470,-0.481,-0.4360,-0.5630)$ & 0.25873 & 0.430 & 0.430 \\
\hline$\psi_{2}$ & $(-0.434,0.4160,-0.693,0.3450,-0.1960)$ & 0.18704 & 0.311 & 0.741 \\
\hline$\psi_{3}$ & $(0.858,0.2390,-0.223,0.3880,0.0790)$ & 0.09055 & 0.151 & 0.892 \\
\hline$\psi_{4}$ & $(-0.1160,-0.752,-0.122,0.6130,0.1750)$ & 0.06476 & 0.108 & 1.000 \\
\hline$\psi_{5}$ & $(-0.0090,0.0740,0.472,0.4050,-0.7790)$ & 0.00012 & 0.000 & 1.000 \\
\hline
\end{tabular}

Table 14. Principal component analysis for L25 OA experimental observations.

\begin{tabular}{|c|c|c|c|c|c|}
\hline Experiment no. & $\psi_{1}(1 \mathrm{st} \mathrm{PC})$ & $\psi_{2}(2 \mathrm{nd} P C)$ & $\psi_{3}(3 \mathrm{rd}$ PC) & $\psi_{4}(4$ th PC) & $\psi_{5}(5$ th PC) \\
\hline 1 & -0.59807 & 0.31557 & 0.51680 & -0.62731 & 0.09539 \\
\hline 2 & -0.61816 & 0.31519 & 0.56575 & -0.33511 & 0.08214 \\
\hline 3 & -1.11187 & 0.02785 & 1.21822 & -0.16878 & 0.10010 \\
\hline 4 & -0.64216 & 0.21643 & 0.97876 & -0.51117 & 0.07336 \\
\hline 5 & -0.67476 & -1.09060 & 0.75589 & -0.39735 & 0.08120 \\
\hline 6 & 0.00126 & -0.10462 & 0.47097 & 0.10060 & 0.09604 \\
\hline 7 & -1.83908 & -0.00132 & 0.52376 & -0.06370 & 0.08572 \\
\hline 8 & -0.87677 & -0.27347 & 0.75684 & -0.62108 & 0.10808 \\
\hline 9 & -1.18017 & -0.21297 & 0.20285 & -0.49641 & 0.09115 \\
\hline
\end{tabular}


Table 15. Calculation of composite principal component (overall quality index) and corresponding $\mathrm{S} / \mathrm{N}$ ratios.

\begin{tabular}{lrr}
\hline Experiment no. & Composite principle component $(\psi)$ & S/N ratio (higher-the-better) \\
\hline 1 & 1.06159 & 0.51910 \\
2 & 0.95947 & -0.35935 \\
3 & 1.66120 & 4.40845 \\
4 & 1.29763 & 2.26304 \\
5 & 1.54291 & 3.76681 \\
6 & 0.50209 & -5.98430 \\
7 & 1.91518 & 5.64421 \\
8 & 1.34675 & 2.58573 \\
9 & 1.31683 & 2.39059 \\
\hline
\end{tabular}

Table 16. Response table (mean) for composite principal component.

\begin{tabular}{lcccc}
\hline \multirow{2}{*}{ Factor } & \multicolumn{4}{c}{ Composite principal component } \\
\cline { 2 - 5 } & Level 1 & Level 2 & Level 3 & Delta \\
\hline Welding current & 1.2274 & 1.1142 & 1.5263 & 0.0 .4120 \\
Voltage & 1.4248 & 1.2830 & 1.1600 & 0.2648 \\
Plate thickness & 0.9701 & 1.1913 & 1.7064 & 0.7363 \\
Total mean grey relational grade $=1.28930$ & \\
\hline
\end{tabular}

Delta $=$ range $($ maximum - minimum $)$

Step 5: Conformity test

Once more, the obtained results have been examined by reconducting the experiment in preview experimental domain upon the same material. Thereafter, Eq. (12) is explored in order to confirm the evaluated results. Finally, it has been found that the evaluated results obtained by overall GRG and CPC based on S/N ratio statistical approach possess potential confirmation, as shown in table 17.

Step 6: Evaluation of significant factors

Finally, ANOVA has been evaluated using Eq. (16) for finding the significant factors among the evaluated result
$A_{3} V_{1} P t_{3}$. It has been found that $P t$ broadly upshots weldment quality in comparison to voltage and current, which poses insignificant effect. It is observed that the plate thickness at 3 level is the upmost significant factor, as shown in tables 18 and 19 for overall GRG and CPC, respectively.

\section{Application of research work}

This study finds application in manufacturing unit/sectors where fabrication works are done using welding processes. This research work assists the researchers to hit upon the optimum setting between the input factors with respect to obtaining the maximum/desirable characteristic index for the said material. This research work could further be implemented to find the optimum setting between input factors based on outputs Multiparameter Characteristic Index (MPCI). This manuscript found its validity not solely analysis the experimental information (data) for MIG welding but also, for unlike welding process. Hence, this manuscript would be the best for analyzing the being developed novel materials.

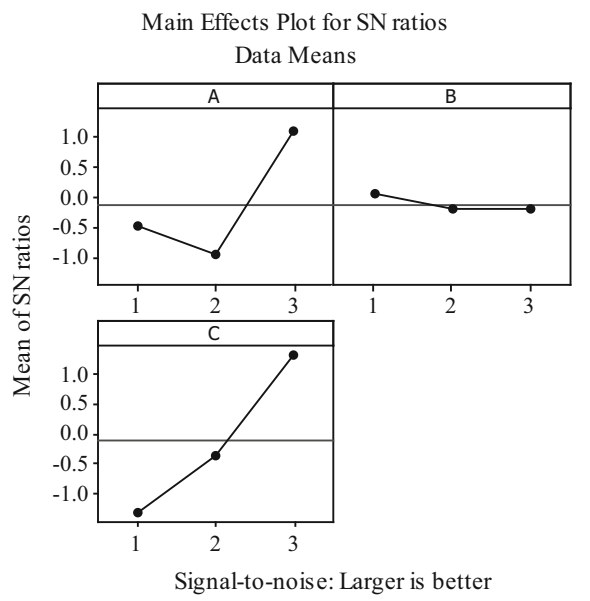

Figure 3. Main effect and $\mathrm{S} / \mathrm{N}$ plot for weldment quality characteristics. 

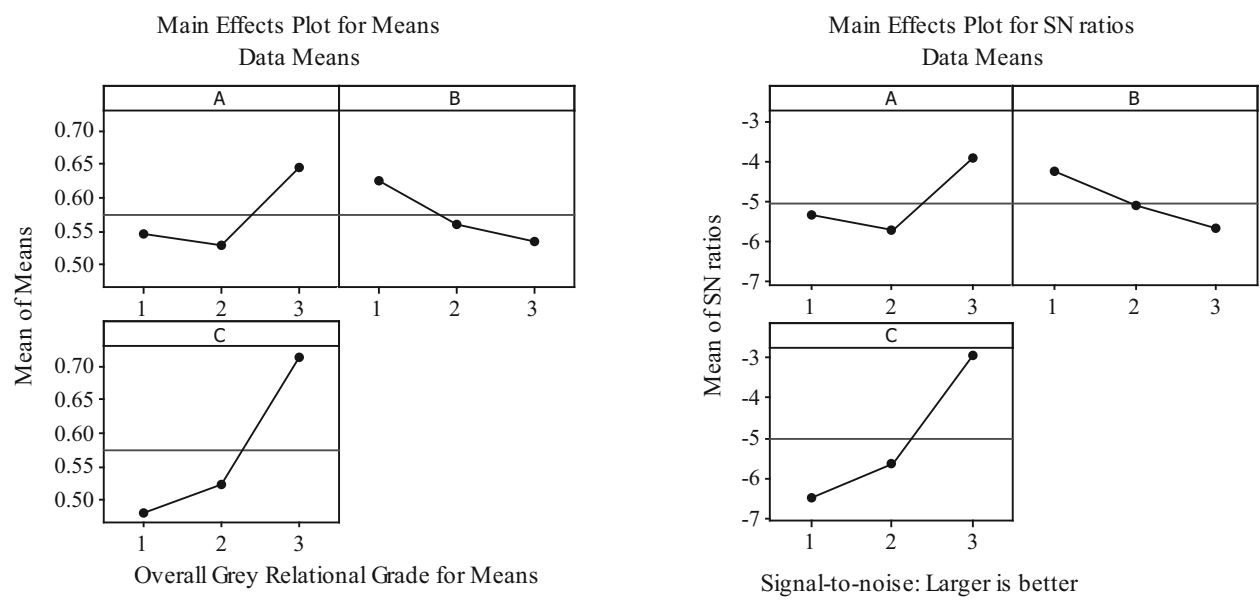

Figure 4. Main effect and $\mathrm{S} / \mathrm{N}$ plot overall grey relational grade (GRG).
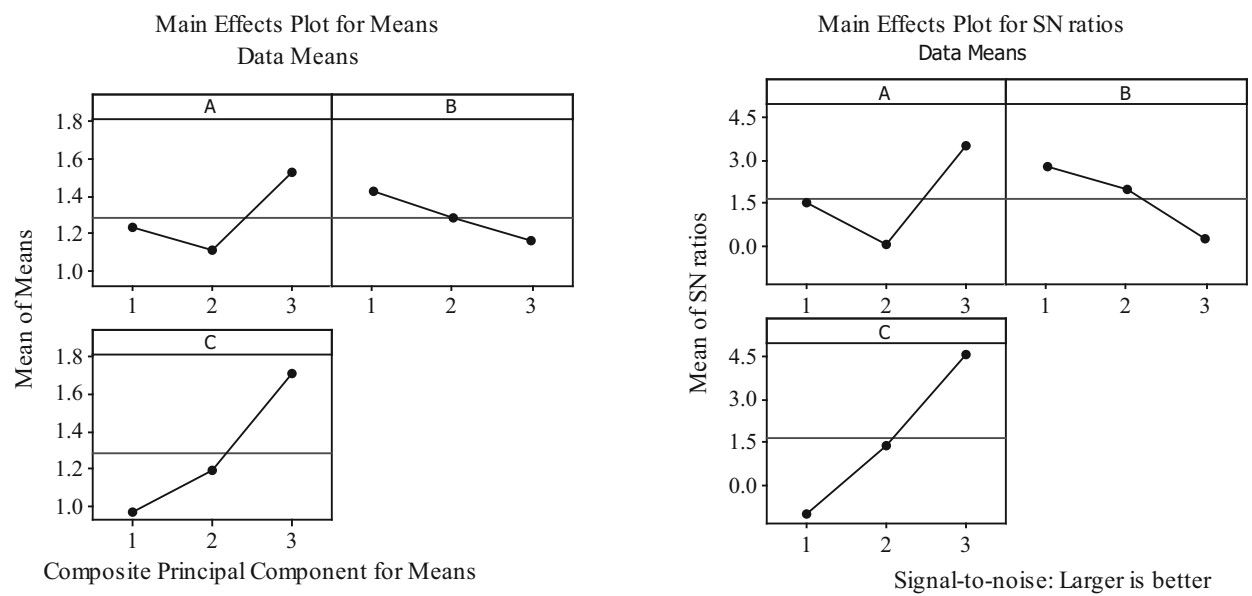

Figure 5. Main effect and $\mathrm{S} / \mathrm{N}$ plot for composite principal component (CPC).

Table 17. Results of confirmatory experiment.

Initial factor setting

Optimal process condition

\begin{tabular}{cc}
\hline Prediction & Experiment \\
$A_{3} V_{1} P t_{3}$ & $A_{3} V_{1} P t_{3}$ \\
& 292.45 \\
& 9.65 \\
& 1.52 \\
& 7.36 \\
-1.53944 & 0.6164 \\
0.83758 & -1.74322 \\
& 0.81816
\end{tabular}

Level of factors

Ultimate tensile strength

Bead width

Reinforcement

Penetration

Dilution

$\mathrm{S} / \mathrm{N}$ ratio of overall grey relational grade

Overall grey relational grade

Improvement in grey relational grade $=0.24454$

$$
\begin{gathered}
A_{1} V_{1} P t_{1} \\
246.41 \\
9.6 \\
3.20 \\
4.90 \\
0.3786 \\
-6.01366 \\
0.50040
\end{gathered}
$$

A. The first segment depicts the effectiveness as well as efficiency of the proposed decision support system (GRA and PCA based on Taguchi approach) for evaluating the optimum setting between input factors.
The conclusions of the present research work are split out into three segments.

\section{Conclusions}


Table 18. Analysis of variance for overall grey relational grade using adjusted SS for tests.

\begin{tabular}{lcccrr}
\hline Source & DF & Sequential SS & Adj SS & Adj MS & F \\
\hline Welding current & 2 & 0.023044 & 0.023044 & 0.011522 & 5.15 \\
Voltage & 2 & 0.012854 & 0.012854 & 0.006427 & 0.163 \\
Plate thickness & 2 & 0.093402 & 0.093402 & 0.046701 & 2.87 \\
Error & 2 & 0.004478 & 0.004478 & 0.002239 & 0.258 \\
Total & 8 & 0.133779 & & & 0.046 \\
\hline
\end{tabular}

Table 19. Analysis of variance for composite principal component using adjusted SS for tests.

\begin{tabular}{lccccc}
\hline Source & DF & Sequential SS & Adj SS & Adj MS & F \\
\hline Welding current & 2 & 0.2719 & 0.2719 & 0.13595 & 1.87 \\
Voltage & 2 & 0.1053 & 0.1053 & 0.05266 & 0.73 \\
Plate thickness & 2 & 0.8564 & 0.8564 & 0.42819 & 5.90 \\
Error & 2 & 0.1452 & 0.1452 & 0.07261 & 0.580 \\
Total & 8 & 1.3788 & & & 0.039 \\
\hline
\end{tabular}

Moreover, the priority weights (importance) against input factors assessed in the context of MIG welding process. It has also been perceived that the proposed decision support system could be utilized in future from the same perspective on dissimilar welding process and materials.

B. The second segment aligns the several vice consequences of the implemented approach.

(a) Implementation of grey relational analysis (GRA) as well as principal component analysis (PCA)-based on Taguchi approach concurrently on the said dilemma facilitated the researchers to robustly evaluate the result.

(b) GRA and PCA approach also found its applicability for tackling optimization dilemma apart from welding context, e.g. evaluation of machining parameters and evaluation of input factors for heat exchanger designing.

(c) GRA and PCA approach is user friendly that is not soliciting the highly skilled. Rather the evaluated results always eliminate multicolinearity of the outputs and transform these corelated objectives into a single objective called MPCI.

(d) $\mathrm{S} / \mathrm{N}$ ratio based on higher is better fundamental fruitfully dealt with MPCI (single out information) for finding optimum synchronization between input factors.

(e) The proposed decision support system found its validity and conformability.

(f) The application of GRA along with the PCA approach concurrently diminishes the chance of error that may occur while the result is evaluated by individual approach.

C. The third segment shows that the consequence of the confirmation yielded an improvement of 0.24454 and 0.66539 in the overall GRG and CPC, respectively. Moreover, the conducted experiments depicted that the plate thickness significantly upshots the MPCI, while welding current dwells with less significant and welding voltage found as upmost ill-significant factor.

Momentous of the aforementioned segments, the proposed decision support system would assist the readers to deal with the optimization dilemmas concerning novel materials in content of any welding in future.

\section{References}

[1] Rowlands H, Antony J and Knowles G 2000 An application of experimental design for process optimization. TQM Mag. 12: $78-83$

[2] Datta S, Nandi G and Bandyopadhyay A 2009 Application of entropy measurement technique in grey based Taguchi method for solution of correlated multiple response optimization problems: a case study in welding. J. Manuf. Syst. 28: $55-63$

[3] Chandel R S, Seow H P and Cheong F L 1997 Effect of increasing deposition rate on the bead geometry of submerged arc welds. J. Mater. Process. Technol. 72: 124-128

[4] Jiang Q, Yajiang L, Juan W and Lei Z 2011 Characterization on strength and toughness of welded joint for Q550 steel. Indian Acad. Sci.. Bull. Mater. Sci. 34: 161-167

[5] Farias J P, Scotti A, De P S, Balsamo S and Surian E 2004 The effect of wollastonite on operational characteristics of AWS E6013 electrodes. J. Brazilian Soc. Mech. Sci. Eng. 26: 317-322

[6] Tarng Y S, Juang S C and Chang C H 2002 The use of greybased Taguchi methods to determine submerged arc welding process parameters in hardfacing. J. Mater. Process. Technol. 128: 1-6 
[7] Lung K P, Wang C C, Wei S L and Sher H F 2007 Optimizing multiple quality characteristics via Taguchi methodbased Grey analysis. J. Mater. Process. Technol. 182: 3107-116

[8] Ilo S, Just C and Xhiku F 2012 Optimisation of multiple quality characteristics of hardfacing using grey-based Taguchi method. Mater. Des. 33: 459-468

[9] Bai Y, Gao H M and Qiu L 2010a Droplet transition for plasma-MIG welding on aluminium alloys. Trans. Nonferrous Metals Soc. China 20: 2234-2239

[10] Bai Y, Gao H M, Wu L, Ma Z H and Cao N 2010b Influence of plasma-MIG welding parameters on aluminum weld porosity by orthogonal test. Trans. Nonferrous Metals Soc. China 20: 1392-1396

[11] Zhang L J, Ning J, Zhang X J, Zhang G F and Zhang J X 2015 Single pass hybrid laser-MIG welding of 4-mm thick copper without preheating. Mater. Des. 74: 1-18
[12] Maggiolino S and Schmid C 2008 Corrosion resistance in FSW and in MIG welding techniques of AA6XXX. J. Mater. Process. Technol. 197: 237-240

[13] Nagesh D S and Datta G L 2002 Prediction of weld bead geometry and penetration in shielded metal-arc welding using artificial neural networks. J. Mater. Process. Technol. 123: $303-312$

[14] Murugan N and Gunaraj V 2005 Prediction and control of weld bead geometry and shape relationships in submerged arc welding of pipes. J. Mater. Process. Technol. 168: 478-487

[15] Shen S, Oguocha I N A and Yannacopoulos S 2012 Effect of heat input on weld bead geometry of submerged arc welded ASTM A709 Grade 50 steel joints. J. Mater. Process. Technol. 212: 286-294

[16] Lee J I and Um K W 2000 A prediction of welding process parameters by prediction of back-bead geometry. J. Mater. Process. Technol. 8: 106-113 